\title{
Risk-reducing mastectomy rates in the US: a closer examination of the Angelina Jolie effect
}

\author{
Alexander Liede $^{1} \cdot$ Mona Cai $^{1} \cdot{\text { Tamara Fidler } \text { Crouter }^{1,2} \cdot \text { Daniela Niepel }^{3} \cdot \text { Fiona Callaghan }^{1} \cdot \text { D. Gareth Evans }}^{4,5}$
}

Received: 19 April 2018 / Accepted: 3 May 2018 / Published online: 28 May 2018

(c) The Author(s) 2018

\begin{abstract}
Purpose In 2013, Angelina Jolie disclosed in the New York Times (NYT) that she had undergone risk-reducing bilateral mastectomy (RRBM) after learning that she was a BRCA1 mutation carrier. We examined the rates of $B R C A$ testing and RRBM from 1997 to 2016, and quantified trends before and after the Jolie op-ed.

Methods This observational study of insurance claims data representative of the commercially-insured US population (Truven MarketScan ${ }^{\circledR}$ database) measured $B R C A$ testing and RRBM rates among females $\geq 18$ years. Censoring events were breast cancer or ovarian cancer diagnosis, last follow-up date (September 2016), or death. Interrupted time series analyses were used to quantify trends before and after the op-ed.

Results Angelina Jolie's NYT op-ed led to a statistically significant increase in the uptake of genetic testing and in RRBM among women without previous diagnosis of breast or ovarian cancer in the US population, and in women who did not undergo testing for $B R C A$ ( $P<0.0001$ for both). The rate (slope) of RRBM among women who were previously tested for $B R C A(P=0.70)$ was unchanged. After excluding women with in-situ tumors, the editorial's effect became less pronounced, suggesting that high-risk women with in-situ breast cancers were most influenced by Jolie's announcement.

Conclusion The Angelina Effect-a term coined by Time magazine to describe the rise in internet searches related to breast cancer genetics and counseling-represents a long-lasting impact of celebrity on public health awareness as significant increases in genetic testing and mastectomy rates were observed and sustained in subsequent years.
\end{abstract}

Keywords Bilateral mastectomy $\cdot$ Genetic testing $\cdot$ BRCA mutation

Electronic supplementary material The online version of this article (https://doi.org/10.1007/s10549-018-4824-9) contains supplementary material, which is available to authorized users.

D. Gareth Evans

gareth.evans@cmft.nhs.uk

1 Center for Observational Research, Amgen Inc., Thousand Oaks, CA, USA

2 SimulStat Incorporated, Solana Beach, CA, USA

3 Global Medical Affairs, Amgen GmbH, Zug, Switzerland

4 Genomic Medicine, Manchester Academic Health Science Centre, The University of Manchester, Manchester, UK

5 Central Manchester University Hospitals NHS Foundation Trust, Saint Mary's Hospital, Oxford Road, Manchester M13 9WL, UK

\section{Introduction}

On May 14, 2013, actress, filmmaker, and humanitarian Angelina Jolie disclosed in an open editorial (op-ed) to the New York Times entitled "My Medical Choice" that she had learned she was a BRCAl mutation carrier and had undergone a risk-reducing bilateral mastectomy procedure with reconstruction [1]. Women with inherited mutations in the $B R C A 1$ or $B R C A 2$ genes represent a population at greatest risk of developing early-onset breast cancer and ovarian cancer, and, therefore, face difficult decisions around whether to have risk-reducing surgery or opt for increased surveillance for early detection [2-6]. In her letter, Angelina Jolie reflected on her personal process in dealing with the implications, and emphasized that women should make their own informed choices.

"For any woman reading this, I hope it helps you to know you have options. I want to encourage every woman, especially if you have a family history of 
breast or ovarian cancer, to seek out the information and medical experts who can help you through this aspect of your life, and to make your own informed choices" [1]

Angelina Jolie's decision generated publicity worldwide, and led to increased awareness and interest in hereditary breast cancer and genetic testing, including publications in the medical domain evaluating this Angelina Jolie Effect [7, 8]. In December 2016, Desai and Jena [9] published on mastectomy rates in the United States using a large representative health insurance database (MarketScan $®$, Truven Health Analytics), and reported that the Effect was not sustained over a period beyond 60 days. The Desai and Jena report had significant limitations including short follow-up time (monthly mastectomy rates for each of the 7 months following Ms. Jolie's editorial). More importantly, the lack of censoring resulted in the inclusion of women with a diagnosis of cancer, including breast cancer and ovarian cancer, which may have meant that many therapeutic rather than prophylactic mastectomy procedures were included, diluting any trend. Using the identical MarketScan ${ }^{\circledR}$ data source, the objective of our study was to examine the rates of $B R C A$ genetic testing and rates of risk-reducing mastectomies from 1997 to 2016, applying methods that censor upon diagnosis of breast and ovarian cancer, and to measure changes in these trends upon the Jolie op-ed publication on May 14, 2013.

\section{Methods}

\section{Data source}

For our analysis, we used the MarketScan ${ }^{\circledR}$ Commercial Claims and Encounters and Medicare Supplemental and Coordination of Benefits databases (Truven Health Analytics, an IBM Company, Ann Arbor, MI). MarketScan databases represent a large and diverse sample of individuals in the United States who have employer-based health insurance plan from approximately 350 private payers. The de-identified patient-level data captures demographics, enrollment information, inpatient, outpatient, and prescription drug claims. Marketscan includes over 22.3 million individuals covered in 2016 calendar year, 8.6 million adult female covered lives, which represents approximately $7 \%$ of the overall adult female population in the U.S [10].

\section{Study population}

We identified all females 18 years and older from January 1997 through end of follow-up (at the time of data analysis), September 2016. To ensure, we captured a population without cancer (cancers relevant to mastectomy as therapeutic intervention), censoring events were breast or ovarian cancer diagnosis, and administrative end of follow-up (September 2016), or death. All patients had a minimum of 12 months continuous enrollment prior to index date, defined as their baseline period. The index date was first enrollment date plus 365 days. If the individual had multiple continuous enrollment periods, the first enrollment period was used to capture earliest possible genetic testing or cancer diagnosis.

\section{Analysis}

Descriptive analyses were performed for baseline characteristics: age, insurance type, geographic region, and median follow-up duration. Characteristics were provided by calendar periods-1997-2002, 2003-2012, 2013-2016, overall, and for never BRCA tested, and BRCA tested. BRCA cohorts were defined as those with $B R C A$ testing during baseline or follow-up. If a patient was $B R C A$ tested within 30 days of mastectomy, we considered this patient to be never $B R C A$ tested-a conservative approach since we could not be certain from these administrative claims data whether the $B R C A$ test was a factor in the decision to perform prophylactic mastectomy in this short time window.

We identified $B R C A 1$ and $B R C A 2$ genetic testing according to Current Procedural Terminology (CPT), Healthcare Common Procedural Coding System (HCPCS) codes 81211-81217 in outpatient claim. Mastectomy identified based on ICD-9/ICD-10 Procedure codes and CPT codes (listed in Online Resource 1). Breast cancer cases and ovarian cancer cases were censored and identified based on the following ICD-9 CM, or ICD-10 CM (International Classification of Diseases, Ninth or Tenth Revision, Clinical Modification) codes (Online Resource 2).

In separate sensitivity analyses, we censored for in situ breast cancers (ductal, lobular, or unspecified carcinoma in situ) (ICD-9 CM 233.0; ICD-10 CM D50.00-02, D05.9092, D05.80-82, D05.10-12). We examined family history codes for breast and ovarian cancer (Z80.3, Z80.41, respectively) and considered performing further sensitivity analyses, but we determined that it was not feasible since $<1 \%$ of patients had any codes for a family history, and patients who did were already captured using previous $B R C A$ testing.

Incidence rates (IR) of mastectomy were calculated monthly and trends over time were graphed-overall and by $B R C A$ testing status (ever versus never tested), whereby the numerator included women who had a mastectomy during that month and qualified for inclusion in the denominator. Each qualifying patient only counted once and then they were removed from cohort. The denominator for a respective month represented the sum of person-time contributed by each female eligible that month up until 
mastectomy or censoring. Trends over time were evaluated by measuring incidence rate ratio (IRR) and $95 \%$ confidence intervals (CI). IRR was defined as month to month ratio of IR for mastectomies for each time period specified. IRs of $B R C A$ testing were measured monthly and trends plotted over time, whereby the numerator represented who had evidence of at least one BRCA test during that month and qualified for inclusion in the denominator.

We used interrupted time series analyses [11] comparing slopes of incidence trends before and after the op-ed publication date in May 2013. The pre-intervention period was evaluated from January 1, 2003 through May 31, 2013 (right censor date for pre-intervention period used to keep monthly rate for May consistent), and the post-intervention period from June 1, 2013 through September 30, 2016. A quasipoisson regression model was used to model mastectomy incidence rates over time, allowing the model to fit different trend lines before and after May 2013. The quasipoisson regression model is a type of poisson model that is more robust to statistical assumptions and accounts for overdispersion. Autocorrelation was examined to assess the correlation between time points. Analyses were generated using SAS Software, version 9.4 (SAS Institute Inc., Cary, NC), and the time series analyses were performed using R software, version 3.3.2 (The R Foundation, Vienna, Austria).

\section{Results}

The mean follow-up was approximately 2.8 years for overall cohort, median follow-up 2.0 years but was consistently longer among women who had undergone $B R C A$ genetic testing versus non- $B R C A$ tested for all calendar periods (Table 1). Women who had BRCA genetic testing were more likely to be younger, commercially insured, and residing in the Northeast compared with the non-BRCA-tested women. The mean age of women in the 1997-2016 study period was 43.5 (interquartile range, 25 th and 75 th percentiles [IQR]; $31 ; 54)$. Mean age among those who had BRCA testing was 41.9 years (IQR 34;50); whereas the mean age was 43.5 years (IQR 31;54) for those who did not have testing for $B R C A$ mutation in their patient data.

The CONSORT [12] diagram of patient attrition based on the inclusion/exclusion criteria used to identify female beneficiaries with at least 1 year of continuous insurance coverage from January 1997 to September 2016 in the MarketScan database is provided in Online Resource 3. After meeting all inclusion/exclusion criteria, $N=533,753$ women developed breast cancer and $N=81,427$ women developed ovarian cancer during the follow-up period and were censored at that time.

\section{$B R C A$ genetic testing}

In these employer-based insurance claims data, the uptake of $B R C A$ testing - among women without a previous diagnosis of breast or ovarian cancer-began in 2003 (Fig. 1). This may indicate a change in insurance coverage and reimbursement for genetic testing in 2003. An inflection in BRCA testing was evident after May 2013, as reported by Desai and Jenna [9]: the predicted IR jumped from 16.0 (95\% CI $15.2-16.9$ ) to 20.7 (95\% CI 19.5-21.9) $B R C A$ tests per 100,000 women from May to June of 2013 $(P<0.0001)$.

Interrupted time series analysis examining the pre- and post-editorial IRs for $B R C A$ testing indicated that there was an overall increase in $B R C A$ testing after the editorial, but the IRR (slope) of $B R C A$ testing decreased from a $2 \%$ increase in the IR each month to $0.5 \%$ increase $(P<0.0001)$ (Fig. 2).

\section{Risk-reducing mastectomy rates}

In the 2003-2016 period, the association between the uptake of $B R C A$ testing starting in 2003 and the steady increase in mastectomy procedures among women who were tested for BRCA mutations is illustrated (Fig. 3). Monthly mastectomy rates increased after 2007, with possibly a further increase in 2013. Mastectomy rates among women who did not undergo BRCA testing were comparatively low and constant during the study period; for example, 0.29 per 100,000 on September 01, 2006, and 0.56 per 100,000 on September 01, 2016.

The interrupted time series with regression model revealed that, overall, there was a marked difference in the incidence rate of risk-reducing mastectomy (both slope and magnitude) before and after May $2013(P<0.0001$, Fig. 4a) Specifically, there was an increase in the IRR after the Angelina Jolie editorial date, with IR of risk-reducing mastectomy increasing $0.2 \%$ each month before the editorial and $0.9 \%$ each month after May $2013(P=0.0112)$.

There was also a significant effect on the rates of riskreducing mastectomy among women who did not undergo testing for $B R C A(P<0.0001)$ (Fig. 4b). Pre-intervention, the rate of mastectomies remained stable month over month; the IR was, if anything decreasing slightly by $0.04 \%$ each month $(P=0.61)$. Post-intervention, the rate of mastectomies increased each month by about $0.64 \%(P=0.033)$.

Although the rate of mastectomy generally increased over time, the editorial did not have an impact on the rate of risk-reducing mastectomy for women who were previously tested for BRCA $(P=0.70)$ (Fig. 4c). Pre-intervention, the IR was increasing each month by $1.6 \%$, compared to $1.2 \%$ each month post-intervention. 


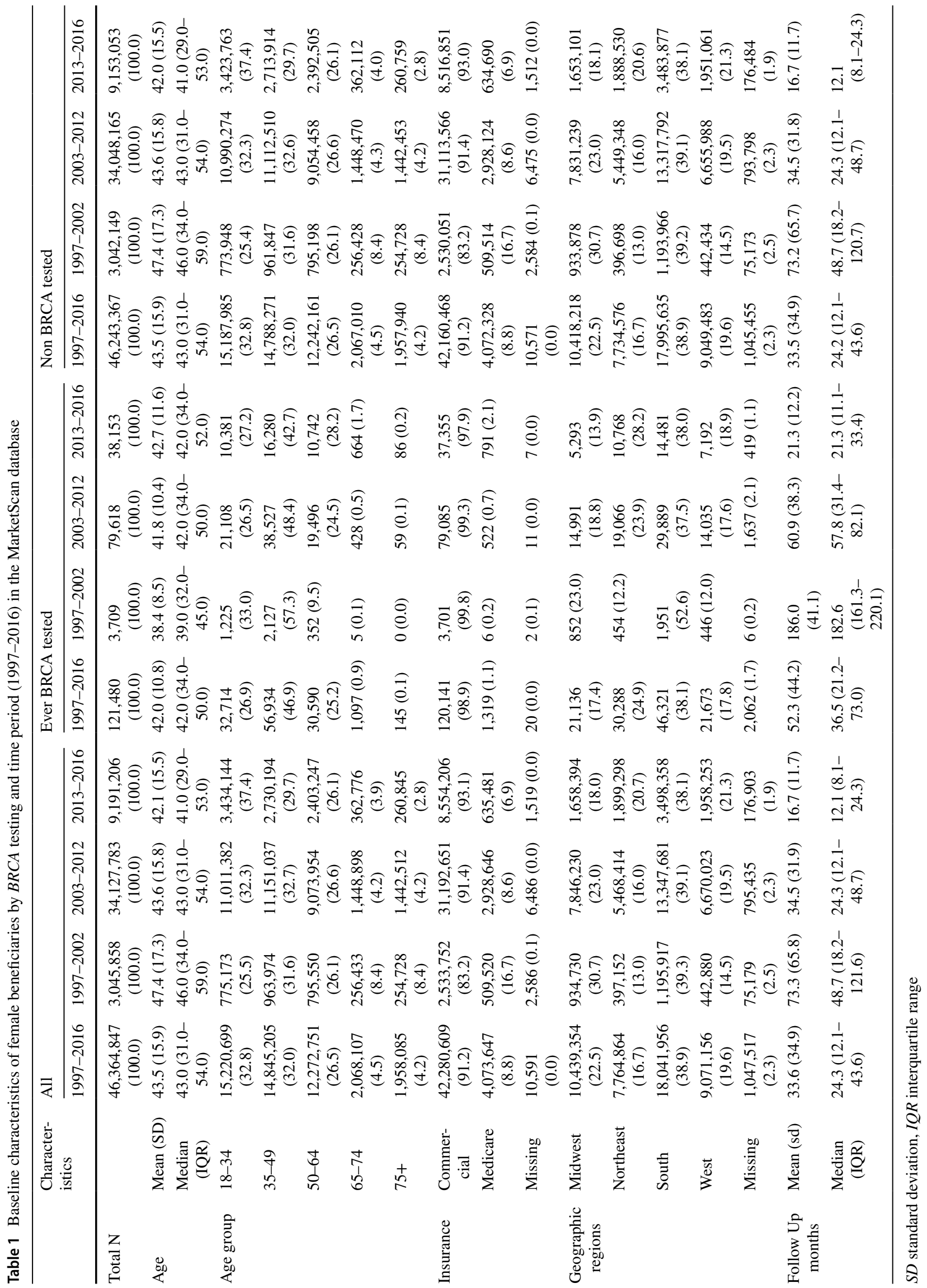




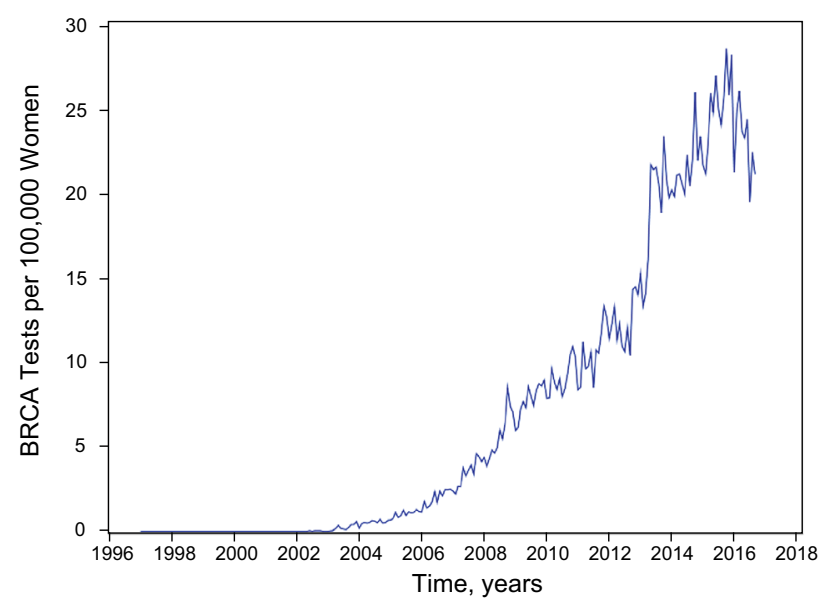

Fig. 1 Monthly incidence rates of BRCA genetic testing among adult female enrollees in MarketScan database (1997-2006)

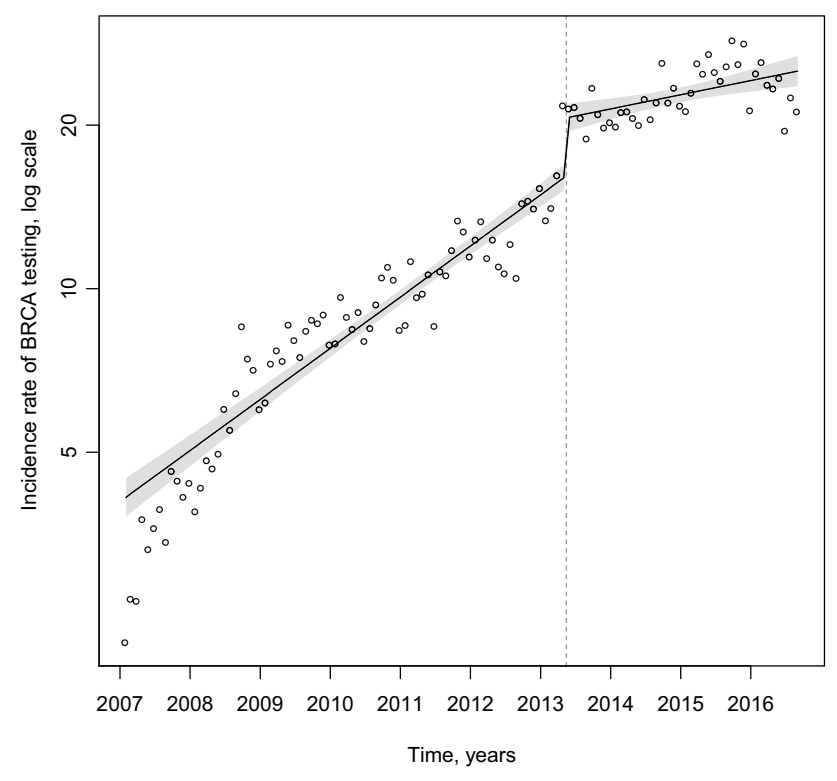

Fig. 2 Interrupted time series analyses of $B R C A$ testing monthly incidence rates per 100,000 among adult female enrollees in MarketScan database (2007-2016) before and after Jolie op-ed on May 14, 2013 (shading depicts 95\% CIs)

\section{Sensitivity analyses}

We excluded patients with in-situ breast cancers in our censoring approach in separate analyses. Overall, the results were similar: the rates of prophylactic mastectomy increased significantly after the editorial for women who were not previously tested $(P<0.0001)$ and the combined $(B R C A$ tested and non-tested) population $(P<0.0001)$. The estimates for the month-on-month IRs remained similar to the previous analyses, however, some of the $P$ values changed:

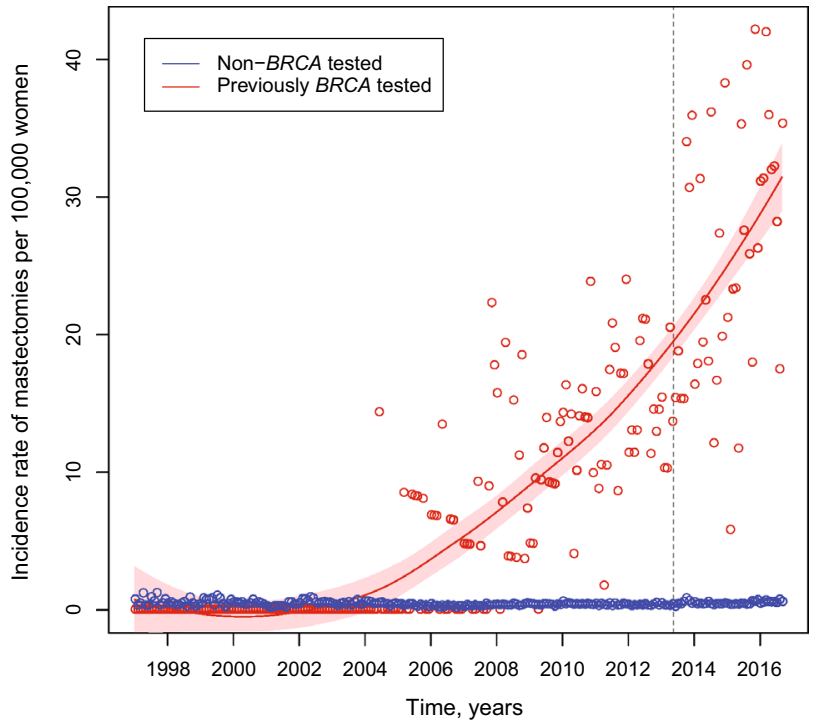

Fig. 3 Monthly incidence rates of risk-reducing mastectomy procedures by BRCA testing among adult female enrollees in MarketScan database (2003-2016) (trend lines fitted using loess curves, and shading depicts $95 \%$ CIs)

the differences in the slopes were no longer significant for women who were not previously $B R C A$ tested $(P=0.28)$ and all women $(P=0.19)$. The results for women who were previously tested for the $B R C A$ gene were similar to the previous analysis: the editorial did not have a significant impact on the rates of prophylactic mastectomy overall $(P=0.24)$ or on the slope of the IR $(P=0.09)$.

Finally, in order to correct for the violation of the autocorrelation in some of the models, we re-ran the interrupted time series models with robust variance estimates. Generally, we obtained similar results, except for the analysis of women who were not previously tested for $B R C A$. The estimates for the IRs were the same, but the change in slope of the IR before and after the editorial was no longer significant $(P=0.059)$.

\section{Discussion}

This study describes that a large and immediate increase in $B R C A$ testing was observed among commercially insured women 18 years of age and older in the United States following Angelina Jolie's New York Times editorial published on May 14, 2013. Desai and Jenna reported similar findings using the same data source, but in contrast to these previous analyses, we examined a much longer time period spanning over 20 years (1997-2016) and, importantly, women were censored at breast or ovarian cancer diagnosis to accurately represent incidence of prophylactic or risk-reducing mastectomies among women and among those who have and have 
Fig. 4 Interrupted time series analyses of risk-reducing mastectomy monthly incidence rates before and after Jolie op-ed on May 14, 2013 (shading depicts $95 \% \mathrm{CIs}$ ). a Incidence rates of risk-reducing mastectomy procedures per 100,000 . b Incidence rates of risk-reducing mastectomy procedures among never $B R C A$ tested per 100,000. c Incidence rates of risk-reducing mastectomy procedures among $B R C A$ tested per 100,000

not had previous $B R C A$ genetic testing. In the interrupted time series analyses, we report a statistically significant increase in risk-reducing mastectomy procedures pre- versus post-publication of the Jolie op-ed among all women and among those who had not undergone genetic testing.

In the MarketScan ${ }^{\circledR}$ employer-based insurance claims database, $B R C A$ testing began in 2003, suggesting a seminal event relating to policy or access took place and led to an immediate uptake of genetic testing. In truth, Myriad Genetics, Inc. (Salt Lake City, UT) had launched a commercial full-length gene sequencing test for $B R C A 1$ and $B R C A 2$ in November 1996, outpacing the American Medical Association CPT codes used for health insurance reimbursement; CPT codes for genetic testing only went into effect in 2003 [13]. The introduction of new codes, which can result in misclassification bias, emphasizes the importance of recognizing the innate strengths and limitations of reimbursement claims databases such as MarketScan ${ }^{\circledR}$ or Medicare, [14] particularly when measuring trends in genetic testing or other interventions over time. Health insurance claims databases are also subject to changes in government policy affecting access and reimbursement. For example, the United States government introduced laws in recent years to prevent genetic discrimination from health insurers and employers: the Genetic Information Nondiscrimination Act (GINA) (2008), [15] the Affordable Care Act (2010), [16] and the GINA-required modification to HIPAA (2013). The introduction of these laws did not directly correspond with increases in BRCA testing rates in our study.

Risk-reducing mastectomy trends remained stable or unchanged for women who had a BRCA test; specifically, a steady increase was observed after May 14, 2013, but the slope in the rate of mastectomy procedures remained stable before versus after the Jolie op-ed. This finding suggests either that women who embarked on genetic testing, who have their cancer risk level well defined, were less influenced by the Jolie op-ed, or that the increased volume of individuals undergoing genetic testing included many women with a lower likelihood of having genetic predisposition and resultant lower proportion of positive test results. Based on the sensitivity analyses, the population of women most influenced by Jolie's announcement may have been women with a diagnosis of in-situ carcinomas of the breast (ductal, lobular, or unspecified carcinoma in situ), considered stage 0 or a "pre cancer". It is known that ambiguity around cancer risk-particularly among
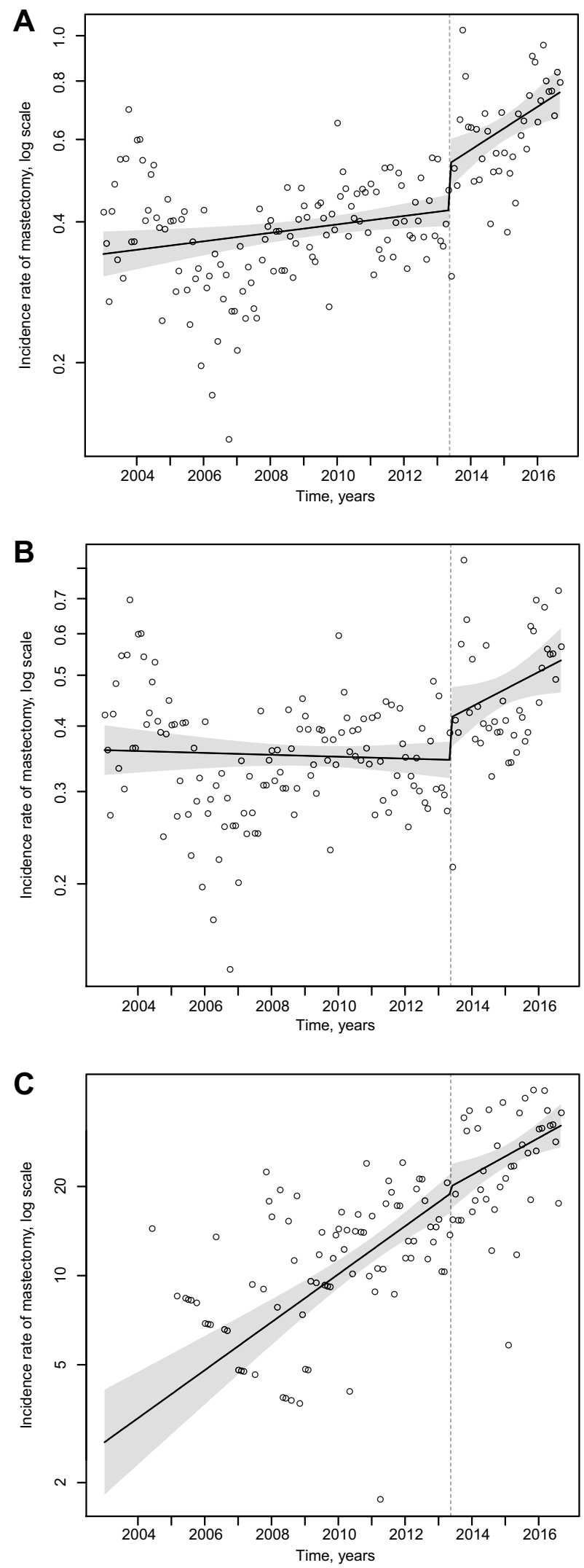
women with in-situ cancers, [17-20] women in high risk breast-ovarian cancer families who decline predictive testing $[21,22]$ or who receive uninformative results, [23, 24] or $B R C A$ mutation carriers who do not proceed with risk-reducing surgeries [25-28]—can be associated with higher cancer-related distress and anxiety levels. A celebrity like Angelina Jolie announcing her decision to have a surgical procedure to prevent future cancer may have, to a larger extent, influenced these women facing a degree of uncertainty about future breast cancer risk to proceed more aggressively towards prophylactic surgery.

The strengths of our study are that we addressed shortcomings of previous reports in a large representative data set of the United States population. We handled the challenge of inaccurately measuring therapeutic mastectomy versus true risk-reducing mastectomies by using a persontime approach with censoring upon occurrence of breast or ovarian cancer. We utilized an interrupted time series regression analysis to test for the magnitude and statistical significance of the Jolie effect over time. We confirmed previous observations of the uptake of genetic testing and refute reports that the mastectomy or $B R C A$ testing trends subsided quickly. Our analysis of monthly rates of mastectomy over a study period in excess of 20 years and with 3.33 years of follow up after the Jolie op-ed date allowed for sufficient time post-genetic testing to measure mastectomy procedures that may occur in excess of 9 months after genetic testing [29]. This is an important consideration in the interpretation of the Desai and Jenna [9] analyses as the 60-, 90-, and 180- day mastectomy rates post-genetic testing are not only limited in follow up but also subject to error and bias because health insurance claims data are subject to delays, a median of 43 days delay in a recent validation study [30] of bone metastasis diagnostic codes using electronic medical record data of breast cancer patients as the gold standard. A key limitation is that the results of $B R C A$ mutation testing (and family history) were not available in the MarketScan ${ }^{\circledR}$ data, and, therefore, it remains unclear whether the rates of mastectomy among women who underwent $B R C A$ testing, which increased after the Jolie op-ed publication, can be specifically extrapolated to the high-risk women found to have a mutation in either BRCA1 or BRCA2.

Overall, the Angelina Jolie Effect represents a long-lasting impact of a celebrity on public health awareness with significant increases in genetic testing and mastectomy rates, which were measurable and sustained over subsequent several years.

Author Contributions AL, DN, FC, MC are employees of Amgen Inc. and own Amgen stock. TFC is an employee of SimulStat Incorporated, work contracted through Amgen Inc. DGE received travel reimbursements from Amgen and Astrazeneca in the past. No other relationships or activities that could appear to have influenced the submitted work.

\section{Compliance with ethical standards}

Conflict of interest This research was not supported by any specific funding. Statistical analysis and writing support provided by Amgen Inc.

Open Access This article is distributed under the terms of the Creative Commons Attribution 4.0 International License (http://creativeco mmons.org/licenses/by/4.0/), which permits unrestricted use, distribution, and reproduction in any medium, provided you give appropriate credit to the original author(s) and the source, provide a link to the Creative Commons license, and indicate if changes were made.

\section{References}

1. Jolie A (2013) My medical choice. New York Times, May 14, 2013. http://www.nytimes.com/2013/05/14/opinion/my-medic al-choice.html. Accessed 20 May 2013

2. Antoniou AC, Hardy R, Walker L, Evans DG, Shenton A, Eeles R, Shanley S, Pichert G, Izatt L, Rose S et al (2008) Predicting the likelihood of carrying a BRCA1 or BRCA2 mutation: validation of BOADICEA, BRCAPRO, IBIS, Myriad and the Manchester scoring system using data from UK genetics clinics. J Med Genet 45(7):425-431

3. Claus EB, Risch N, Thompson WD (1994) Autosomal dominant inheritance of early-onset breast cancer. Implications for risk prediction. Cancer 73(3):643-651

4. Evans DG, Graham J, O'Connell S, Arnold S, Fitzsimmons D (2013) Familial breast cancer: summary of updated NICE guidance. BMJ 346:f3829

5. Gail MH, Brinton LA, Byar DP, Corle DK, Green SB, Schairer C, Mulvihill JJ (1989) Projecting individualized probabilities of developing breast cancer for white females who are being examined annually. J Natl Cancer Inst 81(24):1879-1886

6. Moyer VA (2014) Risk assessment, genetic counseling, and genetic testing for BRCA-related cancer in women: U.S. Preventive Services Task Force recommendation statement. Ann Intern Med 160(4):271-281

7. Nisker J (2013) A public health education initiative for women with a family history of breast/ovarian cancer: why did it take Angelina Jolie? J Obstet Gynaecol Can 35(8):689-691

8. Evans DG, Barwell J, Eccles DM, Collins A, Izatt L, Jacobs C, Donaldson A, Brady AF, Cuthbert A, Harrison R et al (2014) The Angelina Jolie effect: how high celebrity profile can have a major impact on provision of cancer related services. Breast Cancer Res 16:442-446

9. Desai S, Jena AB (2016) Do celebrity endorsements matter? Observational study of BRCA gene testing and mastectomy rates after Angelina Jolie's New York Times editorial. BMJ 355:i6357

10. US Census Bureau. https://factfinder.census.gov/faces/tableservi ces/jsf/pages/productview.xhtml?pid=ACS_16_1YR_B0100 1\&prodType $=$ table. Accessed 5 Dec 2017

11. Ramsay CR, Matowe L, Grilli R, Grimshaw JM, Thomas RE (2003) Interrupted time series designs in health technology assessment: lessons from two systematic reviews of behavior change strategies. Int J Technol Assess Health Care 19(4):613-623

12. von Elm E, Altman DG, Egger M, Pocock SJ, Gotzsche PC, Vandenbroucke JP, Initiative S (2007) Strengthening the reporting of observational studies in epidemiology (STROBE) statement: guidelines for reporting observational studies. BMJ 335(7624):806-808 
13. Logue LJ (2003) Genetic testing coverage and reimbursement: a provider's dilemma. Clin Leadersh Manag Rev 17(6):346-350

14. Mues KE, Liede A, Liu J, Wetmore JB, Zaha R, Bradbury BD, Collins AJ, Gilbertson DT (2017) Use of the medicare database in epidemiologic and health services research: a valuable source of real-world evidence on the older and disabled populations in the US. Clin Epidemiol 9:267-277

15. National Human Genome Research Institute (NHGRI): The Genetic Information Nondiscrimination Act (GINA) of 2008. https://www.genome.gov/27568492/the-genetic-informatio n-nondiscrimination-act-of-2008/. Accessed 21 Dec 2017

16. U.S. Department of Health and Human Services: Affordable Care Act. https://www.hhs.gov/healthcare/about-the-aca/index.html. Accessed 21 Dec 2017

17. Gregorowitsch ML, van den Bongard H, Young-Afat DA, Pignol JP, van Gils CH, May AM, Verkooijen HM (2017) Severe depression more common in patients with ductal carcinoma in situ than early-stage invasive breast cancer patients. Breast Cancer Res Treat

18. Ganz PA (2010) Quality-of-life issues in patients with ductal carcinoma in situ. J Natl Cancer Inst Monogr 2010(41):218-222

19. Kennedy F, Harcourt D, Rumsey N, White P (2010) The psychosocial impact of ductal carcinoma in situ (DCIS): a longitudinal prospective study. Breast 19(5):382-387

20. Mertz BG, Duriaud HM, Kroman N, Andersen KG (2017) Pain, sensory disturbances and psychological distress are common sequelae after treatment of ductal carcinoma in situ: a cross-sectional study. Acta Oncol 56(5):724-729

21. Lodder L, Frets PG, Trijsburg RW, Klijn JG, Seynaeve C, Tilanus MM, Bartels CC, Meijers-Heijboer EJ, Verhoog LC, Niermeijer MF (2003) Attitudes and distress levels in women at risk to carry a BRCA1/BRCA2 gene mutation who decline genetic testing. Am J Med Genet A 119A(3):266-272

22. Lerman C, Hughes C, Lemon SJ, Main D, Snyder C, Durham C, Narod S, Lynch HT (1998) What you don't know can hurt you: adverse psychologic effects in members of BRCA1-linked and BRCA2-linked families who decline genetic testing. J Clin Oncol 16(5):1650-1654
23. O’Neill SC, DeMarco T, Peshkin BN, Rogers S, Rispoli J, Brown K, Valdimarsdottir H, Schwartz MD (2006) Tolerance for uncertainty and perceived risk among women receiving uninformative BRCA1/2 test results. Am J Med Genet C Semin Med Genet 142C(4):251-259

24. Dorval M, Gauthier G, Maunsell E, Dugas MJ, Rouleau I, Chiquette J, Plante M, Laframboise R, Gaudet M, Bridge PJ et al (2005) No evidence of false reassurance among women with an inconclusive BRCA1/2 genetic test result. Cancer Epidemiol Biomark Prev 14(12):2862-2867

25. Ertmanski S, Metcalfe K, Trempala J, Glowacka MD, Lubinski J, Narod SA, Gronwald J (2009) Identification of patients at high risk of psychological distress after BRCA1 genetic testing. Genet Test Mol Biomark 13(3):325-330

26. Metcalfe KA, Mian N, Enmore M, Poll A, Llacuachaqui M, Nanda S, Sun P, Hughes KS, Narod SA (2012) Long-term follow-up of Jewish women with a BRCA1 and BRCA2 mutation who underwent population genetic screening. Breast Cancer Res Treat 133(2):735-740

27. Hooker GW, King L, Vanhusen L, Graves K, Peshkin BN, Isaacs C, Taylor KL, Poggi E, Schwartz MD (2014) Long-term satisfaction and quality of life following risk reducing surgery in BRCA1/2 mutation carriers. Hered Cancer Clin Pract 12(1):9

28. Liede A, Fairchild A, Friedman S, Amelio J, Hallett DC, Mansfield CA, Metcalfe KA (2016) Abstract P2-09-09: risk-reducing surgery and cancer-related distress among female BRCA1 and BRCA2 mutation carriers, vol 76

29. Evans DG, Wisely J, Clancy T, Lalloo F, Wilson M, Johnson R, Duncan J, Barr L, Gandhi A, Howell A (2015) Longer term effects of the Angelina Jolie effect: increased risk-reducing mastectomy rates in BRCA carriers and other high-risk women. Breast Cancer Res 17:143

30. Liede A, Hernandez RK, Roth M, Calkins G, Larrabee K, Nicacio L (2015) Validation of international classification of diseases coding for bone metastases in electronic health records using technology-enabled abstraction. Clin Epidemiol 7:441-448 